\title{
Moving critical management education to praxis: integrating professional services within the critical classroom
}

Moving critical management education to praxis

Suzette Dyer

Waikato Management School, University of Waikato, Hamilton, New Zealand

Heather Lowery-Kappes

University of Waikato, Hamilton, New Zealand, and

Fiona Hurd

Auckland University of Technology, Auckland, New Zealand

\begin{abstract}
Purpose - This paper details how we adapted a critically informed third-year career management and development course to address an identified gap in our Human Resource Management students learning at both practical and theoretical levels. In order to address this gap, we explored and challenged the aims of our critically informed pedagogy, and alongside our campus career development services, collaboratively redesigned the course to enhance theoretical and practical learning outcomes of students.

Design/methodology/approach - We detail changes made through three stages of curriculum redesign and provide an exploratory analysis of 106 student reflections on the third iterative redesign. This exploratory analysis focuses on student learning outcomes resulting from their engagement with the career practitioner and the revised course content.

Findings - Students found the course theoretically challenging and practically relevant and were readily able to incorporate career theory into descriptions of their own careers. However, more significantly, students were also able to situate themselves within a wider critique of the context of careers, demonstrating the development of critical reasoning skills and moving towards practical and critical action, demonstrating praxis.

Originality/value - Our experience provides an example of bridging the seeming paradox of critical pedagogy and practice. Specific details of curriculum design may be of interest to those looking to improve both theoretical and practice engagement.
\end{abstract}

Keywords Praxis, Critical pedagogy, Career management and development

Paper type Research paper

\section{Introduction}

The call for business educators to focus on "relevance" is often associated with concerns about the seeming disconnect between the perceived abstract theorising associated with academia and the practicalities associated with the business world (Paton et al., 2014). This "practice turn" in management education (Wall, 2016) has been the centre of scholarly debate for two decades (Ramsey, 2011), largely concerning the place of theory and critique alongside (or in contrast to) practice. For critical management educators, aligning curricula to immediate business needs may be at odds with critical aspirations to challenge managerialism (Alvesson and Willmott, 1992) and the primacy of organisational efficiency and profit accumulation over all else (Fenwick, 2005).

(C) Suzette Dyer, Heather Lowery-Kappes and Fiona Hurd. Published in Journal of Work-Applied Management. Published by Emerald Publishing Limited. This article is published under the Creative Commons Attribution (CC BY 4.0) licence. Anyone may reproduce, distribute, translate and create derivative works of this article (for both commercial and non-commercial purposes), subject to full attribution to the original publication and authors. The full terms of this licence may be seen at http:// creativecommons.org/licences/by/4.0/legalcode

The authors would like to thank the reviewers.

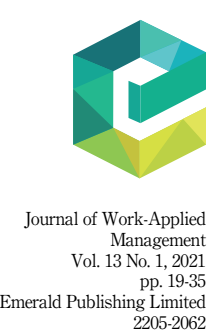

DOI 10.1108/JWAM-10-2020-0042
Received 5 October 2020 Revised 2 November 2020 Accepted 4 December 2020 
JWAM

13,1

Indeed, we have long concurred with Paton et al.'s (2014, p. 271) position that "university priorities are different from business practice and must remain so". Moreover, as selfproclaimed critical management educationalists, we were sceptical of the "practice-relevant" turn, viewing this as undermining the academic role to develop critically conscious citizens and as a move towards upholding what Clegg and Dunkerley (1980) described as the business school role of creating docile functionaries who can reliably sustain hegemonic power relations (Humphries and Dyer, 2005). Thus, our position in this debate has been to view practice relevance as more closely aligned with functionality than criticality and as a challenge to our emancipatory aspirations to empower students to engage in transformational change in their future working lives.

Hence, we have applied a critical approach to all our teaching, including in the undergraduate human resource management (HRM) course on career management and development within a New Zealand business school context that forms the context of this article. Studying careers certainly falls within the ambit of work-based learning as this helps students advance their "work-related aspirations and interests" (Lester and Costley, 2010). That is, career management and development skills are practically relevant to all graduates who must navigate education-to-work transitions (Janse van Rensburg and Goede, 2020); and more so for HRM graduates who might influence the careers of others in their future job roles. Notwithstanding these practicalities, the overarching priorities embedded in the course were to critique the concept of career and to develop the critical reasoning of students.

While we had significant success in developing critical reasoning (Dyer and Hurd, 2018, $2016,2015)$, it became apparent that new cohorts were not enjoying the course, developing the same level of criticality or seeing connections between the curricula and personal career aspirations or HRM practice, compared to previous years. Some students began questioning "how is this relevant to me"? We could see that there were two key gaps, one being a gap between our critical aspirations and the level of student (dis)engagement with theory and critical reflexivity and the second being a skills-based gap in student understanding of the practice, management and impact of career development. This insight presented a pedagogical "crisis"; we had based our practice on critiquing managerialism and the functionality of business school education. Yet we seemed unable to achieve prior levels of critique without addressing the "functional" elephant in the room.

These reflexive insights led us to review our position on the apparent dichotomy between criticality and functionality, and in this paper, we present our experience in confronting this paradox through curricula design. The need to integrate theory and practice is not unique to our experience and is well documented (Hayes et al., 2019). However, examples of integrating a critical perspective with industry-based action learning are less well covered. In this paper, we discuss how we engaged with a careers practitioner to cooperatively redevelop a career management and development course with the dual purpose of maintaining our commitment to critical pedagogy and becoming relevant to students. The next section reviews how we apply critical pedagogy. This is followed by a description of the incremental curricula redesign process and method used to gather data on student learning outcomes over a fouryear period. Next, an analysis of the 106 student reflections on the redesigned course is presented, and we conclude by suggesting future research opportunities arising from our experience.

\section{Committing to critical pedagogy in the management classroom}

The aims of critical pedagogy that have guided our teaching include developing critical reasoning of students, providing an emancipatory education experience and creating fairer societies (Freire, 1970, 1992; Perriton, 2007). Like other critical pedagogues, we interpret teaching as a form of political activism. Central to this activism is to locate 
curricula within the broader historical, socio-cultural, political and economic context (Boje and Al Arkoubi, 2009; Kek and Huiiser, 2011), critique systemic discrimination and examine the production and reproduction of discrimination within the context of daily life (Deetz, 1992).

In practice, we favour experiential and action learning techniques (Miller and Maellaro, 2016) and dialogic-based lectures (Paton et al.,2014) to facilitate students to make connections between curricula and the context of their lives, to move them from surface to deep leaning (Entwistle, 2000) and to develop their critical reasoning skills (Pollner, 1991). Our emphasis in classroom discussions has been to deconstruct assumptions embedded in existing frames of reference, situate lived experience within contexts, generate new insights and to encourage learners to consider adopting inclusive ways of managing and organising.

Praxis, that of moving theory to action, sits at the heart of the emancipatory aim of critical education (Walker et al., 2019). Our commitment to praxis has been to focus on bringing a critical lens in to the management classroom and to craft a reflexive learning experience and to develop the critical reasoning of students to enable them to engage in emancipatory acts. In the critical management studies context, such transformative actions might take the form of challenging management theory (Alvesson and Willmott, 1992), engaging in micro-level organisational change (Spicer et al., 2009) or by talking and acting in new ways (Cunliffe et al., 2002). An implicit assumption is that developing critical reasoning, problematising existing hegemonic systems and structures and creating new meaning will somehow empower students to engage in transformative action (Walker et al., 2019).

Critical pedagogy as applied within the context of the career management and development course has facilitated developing critical reasoning among some students, as demonstrated in assessments and class discussions. However, over time, we have witnessed a decline in student ability, or willingness, to engage critically in course material and class discussions compared to previous cohorts. At the same time, some students expressed a disconnection between personal career aspirations or future professional practice by asking "how is this relevant to me"? Despite our emancipatory aspirations, we have paid little attention to developing skills that might help students design satisfying careers or healthful and meaningful organisational career paths. Even less attention was given to exploring how students might reconcile a theoretical critique of the assimilative effects of self-management with the transformational potential of career management and development in practice.

As part of our pedagogical approach, we reflexively engage with student feedback and personal observations to guide future iterations of courses. The next section describes the original course design and incremental changes made in response to these observations and student concerns regarding course design and learning outcomes. This description also provides the context of the current research.

\section{Playing at the edges: original design, refocusing on criticality and a step towards practicality}

The original course, as depicted as version 1 in Table 1 , was conceptually taught in four phases. Phase 1 set the theoretical and contextual foundation for the course by introducing key concepts of critical theory and presenting the broader historic, socio-cultural, political, economic and organisational contexts in which careers are played out. Reflecting our own national setting, New Zealand, this context is characterised by the transformation of the political economy from Keynesianism to neo-liberal globalisation and the introduction and impact of work-place flexibility on careers. Phase 2 focused on evolving definitions of career within this broader context and as expressed in traditional and contemporary career management and development theories, models and concepts. Phase 2 concluded with a critical interpretation of personality and spirituality tests as techniques to assimilate
Moving critical management education to praxis 
JWAM 13,1

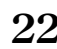

Version 1

Original design

$2 \times 2$ - $\mathrm{h}$ lecture per week

Topic

Phase 1: Introduction

Introduction-Paper Outline,

Expectations, Orientation.

Defining Career

What can we know? Why think about Theory? (Introducing, ontology, epistemology and critical theory)

The future of employment (globalisation and flexibility)

Phase 2: Career Theory

Traditional and contemporary career development and management models Fabricating the Individual Meaning and Spirituality

Phase 3: Careers in Context Individuals in Context: Reshaping the Workforce; Diversity; Dual Careers; Affirmative Action Career Development and Stress Careers in the organisational context (Two weeks of career visitors talking about their career and the career paths in their orgs)

The Future Context of Careers

Assessment

Table 1.

Content, assessment and engagement with career practice overtime
Version 2

Refocusing on criticality

$1 \times 3$ - $\mathrm{h}$ lecture per week
Version 3

A step towards practicality

$1 \times 3$-h lecture per week
Introduction- Paper Outline, Expectations, Orientation.

Defining Career

The Global Context of Career

The Changing Shape of

Employment

Introducing Critical Theory

Traditional and Contemporary

Career Management and

Development Models

Career Management Techniques:

Fabricating the Individual and

Meaning and Spirituality
The Changing Workforce: Diversity; Dual Careers; GEN X and $\mathrm{Y}$;EEO and Affirmative Action

Career Development and Stress Career Development in

Organisations (visitors speak of their careers 2 weeks)
Introducing: Expectations, Orientation. Defining Career Critical Theory

The Global Context of Career The Changing Shape of Employment
Traditional and Contemporary Career Management and Development Models Managing and Developing Your Own Career

Guest Speaker - Career Guidance Councillors talking about career transitions

The Changing Workforce: Diversity; Dual Careers; GEN X and Y; EEO and Affirmative Action Career Development and Stress Understanding Career Management and Development Critically: Fabricating the Individual
(1) Critical Essay

(2) $\log$ Entries $(8 \times 400$ reflective entries on course material)

(3) Essay 2-critically evaluate guest visitors Test

Engagement with Career in Practice
(1) Glossary: individuals allocated a CT term - all collated to form a shared glossary
(2) Group Essay
(3) Individual Essay - critically evaluate guest visitors
(4) Test

Four Guests visitors talking about their careers and the careers available in their respective organisations
Two Guests visitors talking about their careers and the careers available in their respective organisations
(1) Critical Essay
(2) $3 \times$ Mini Assignments
(3) Test

individuals to fit in with changes to organisation structures and careers (Grey, 2004). Phase 3 examined implications of changes in the labour force and the increase reports of stress on individual and organisational careers. Phase 4 focused on individual and orgnanisational

Guest Visitor - career practitioner from the New Zealand Government Careers service 
careers as experienced by four guest speakers, and the course concluded with a critical Moving critical overview of career and end-of-semester test.

Version 1 was supported by four assessments designed to encourage developing critical reasoning and deep learning, augment course content and emphasise reflexivity and meaning-creation (Bisman, 2011). These included an essay examining key concepts of critical theory; a learning log requiring eight entries reflecting different topics covered throughout the course; an essay critically examining the personal and organisational career paths discussed by the four guest speakers and a test.

In response to our observations and student feedback regarding learning outcomes and relevancy, we began to redesign the currculum. As can be seen in version 2 , Table 1 , we responded by refocusing on criticality. This was achieved by reordering the topics in phase 1 , renaming other topics for clarity and by replacing essay 1 and the log entry with two new assessments designed to "help" students grasp critical theory. Our observations and student feedback on this refocus clearly indicated that most struggled with the new design. Further, it was during this time that questions regarding the relevancy of the course intensified.

This prompted us to think about how to embed criticality while enhancing the practical relevance of the course. In version 3, we made three changes to move towards enhancing the practice relevance of the course. First, we reordered the topics and re-sequenced the content within each topic to help build critical appreciation of the emancipatory potentialities and limits of career theories in practice and to make stronger links between course content and lived experience. Second, we replaced the glossary assignment and group essay with the reinstated essay 1 and a refocused essay 2 to strengthen critical reasoning and introduced a new mini Assignment to strengthen the links between course content, lived experience and organisational realities. Third, the guest visitors who previously talked about their personal career journeys were replaced by a guest lecture given by a careers guidance counsellor from the government-funded careers service. This session focussed on career-management skills that enhance successful education-to-employment career transitions.

Version 3 appeared to be successful in terms of student engagement and the development of critical reasoning and practice-relevant skills. Based on these successes, we began to think more deeply about how to strengthen the links between criticality and functionality within the curricula. In the next section, we present the current version of the course, followed by the research design used to gather student feedback on their experiences of version 4 .

\section{Criticality meets functionality in the careers space}

Heartened by the positive outcomes observed from version 3, we began to seek out more overlaps by mapping the goals of career management practice against the goals of critical pedagogy. We did so by mapping Amoroso and Burke (2018) discussion of career management competency as including industry knowledge, discipline mastery, self-awareness, employability competencies and career search skills against critical pedagogical goals.

This mapping, illustrated in Figure 1 below, shows that the development of self-awareness aligns with the pedagogical goal of reflexivity, and the need for industry knowledge to successfully manage careers aligns with the critical concern to understand the wider meso and macro context in which careers are played out.

Recognising these alignments between criticality and functionality uncovered the opportunity to collaborate with the campus careers service to redevelop the course with the purposes of enhancing critical reasoning skills and the practical relevance of the course. As with previous iterations, this collaborative redesign involved changes to the sequencing and content of topics, assessment and function of the guest speaker, as seen in Table 2 below.

Important features of version 4 include new experiential learning exercises and accompanying written assessments designed to help students learn about and reflect on 
JWAM

13,1

\section{4}

Figure 1.

Overlap between career as practice and critical management education aims some of the elements of career management practice and techniques required for managing career. The first of these exercises, presented in lecture 1 , requires students to write down their definition of career and then draw a picture of their career. In pairs, students then discuss their career definitions and consider if and how their pictures depict family and community responsibility, potential career breaks, interest and skill development and leisure time activities, all features embedded in the career eainbow model (Super, 1980). The supportive assessment requires students to write a reflection of their learning from this exercise.

The second exercise involves students attending a 45-min career planning session with a professionally accredited career counsellor. To prepare, students complete assignment 1 and using their career picture as the starting point,consider what they would like to discuss in their session. These individualised sessions focus on career planning and offer students follow-up tasks to help progress their career plans.

In week six, the career counsellor presents a guest lecture summarising the themes to emerge from the career planning sessions. Importantly, this lecture makes explicit links between the career theories covered in the preceding lectures with career practice, as experienced in their individual planning sessions. The final assessment, due at the end of semester, asks students to reflect on whether their definition of career has changed, what issues they might now include or exclude in an updated career pictur, and what course material challenged, affirmed or changed their view on career.

Along with our commitment to criticality, the above activities and engagement with career services were supported by classroom sessions structured around a deep exploration of traditional and contemporary career theory and the socio-cultural and political-economic context of careers. Thus, classroom discussions continued to explore the meaning and power associated with career and the wider political-economic context within which careers occur.

Of all the changes made, version 4 not only challenged our critically informed pedagogical assumptions the most but were designed to simultaneously achieve the paradoxical goals of enhancing criticality and practice-relevancy. In the next section, we present the research design used to examine the learning outcomes from our attempt to do this.

\section{Research design}

The data used in the current study are drawn from a broader four-year research project designed to explore student understandings of careers and changes to work and organisation. This longitudinal approach was intended to mitigate against the impact of contextual factors occurring within one specific cohort and particularly as each class cohort tended to be relatively small (approx. $n=40$ ). The data for the larger study include the three assessment pieces described above for each participant, which provide reflective accounts

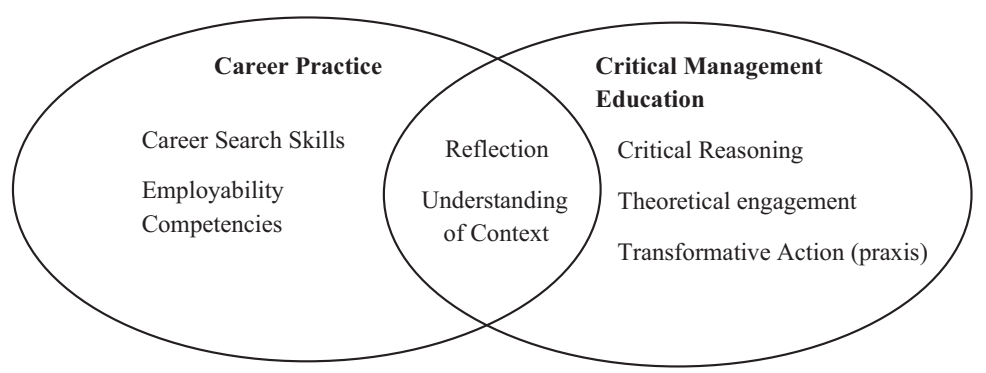

Source(s): Adapted from Amoroso and Burke, 2018 and Dyer and Hurd, 2016 
Topic

Introducing: Expectations,

Orientation. Defining Career

Critical Theory

Linking the Political-Economic

Context to Career

(1) Keynesianism and Traditional Career Management and Development Models

(2) Global neo-liberalism, Changing Shape of Employment and Contemporary Career Management and Development Models

Managing and Developing Your

Own Career

Guest Speaker - Career Guidance

Councillors talking about career

transitions

The Changing Workforce: Diversity; Dual Careers; GEN X and Y; EEO

and Affirmative Action

Career Development and Stress and

Health and Safety

Understanding Career Management

and Development Critically:

Fabricating the Individual

Government Interest in Career:

Education, Training and Labour

Market Outcomes

Review Session: Bringing it all

Together
Engagement with career in practice

Assessment

(1) Reflective Assignments x 3

Reflective Assignment 1

Reflection on Career Drawing-How did you define career? Briefly describe your career picture, or include the picture in the assignment? What did you include in this picture? Why? What issues did you exclude in your drawing? Why? Did your picture of career resemble your definition of career? How?

Reflective Assignment 2

Reflect on your career guidance

session. With your career picture as your starting point what main issues did you think you wanted to discuss when you went to your session? What issues were raised for you in the session? What actions were suggested to help you further develop your career plan? How easily can you implement these actions? Reflective Assignment 3

Reflect upon your initial career picture and definition of career as presented in the first reflective assignment. You need to consider: Whether your initial definition of career has changed since the first reflective assignment? If so, in what ways? If not, why not? How would your picture of your career change now? What issues do you now consider to be part of your career (Why) What issues do you consider to not be part of your career (Why?) What were the two most significant issues raised throughout the course that has led you to reconsider or reaffirm your definition of career? How might these issues affect you in your future career, if not managed? How might these issues affect organisations if not properly managed?

(2) Essay 1: Compare and contrast traditional and contemporary career theories (or metaphors)

(3) Essay 2: Write on a career issue that interests you. You might choose from the list of topics covered throughout the course, or an issue that has not been presented
Career Practitioner help design the course including the three supported Reflective Assignments

Each student attends a 1-h career planning session Career Practitioner provides a guest lecture

\section{Moving critical management education to praxis}


JWAM

13,1

\section{6}

and visual representations of their learning about career. These approaches are recognised for generating rich data to explore individual understandings and worldviews (Mannay, 2010; Dyer and Hurd, 2016).

This broader project purposively coincided with the course redesign. Initial descriptive analysis of the first year of material revealed rich data documenting student experiences of bringing together criticality and functionality within the same educational space.

In accordance with the ethical approval obtained for this research, participation was voluntary, and to avoid feelings of coercion, students were invited to submit their assignments as data for research at the end of semester and after all grades had been finalised. A total of 106 out of the 159 students enrolled in the four-year period submitted their assignments as data. The sample included 70 female and 36 male students, 84 domestic and 22 international students, with the vast majority being young adults undertaking their first undergraduate qualification.

\section{Thematic analysis}

The thematic analysis was conducted according to Braun and Clarke (2006) process. Thus, the initial reading to become familiar with the empirical material was followed by a deeper thematic analysis (Braun and Clarke, 2006) involving a line-by-line reading of each reflection, the development of open codes, looking for repeated patterns and organising these patterns into themes (Braun and Clarke, 2006). The open coding coalesced around fivekey themes within two meta-themes; the course being theoretically challenging yet practically relevant and situating individual careers within micro, meso and macro contexts. These themes were then considered in light of the seven learning aims linked to career practice and critical pedagogy illustrated in Figure 1 above. This analytical framework is illustrated in Table 3 below. We discuss these key findings in the following section.

\section{Findings}

Student reflections on engagement with the career practitioner services, the theoretical content of the course and classroom discussions were captured through the three assessments described above. Analysis of these reflections revealed two sets of themes. Firstly, the students found the course both theoretically challenging and practically relevant. Secondly, reflections demonstrate students engaging in critical reasoning by situating themselves and their careers within micro (individual), meso (organisational) and macro (wider political economy) contexts. Throughout these reflections, there is also evidence of action related to their career practice and associated with their critical reasoning. We discuss each of these in turn, drawing on indicative quotes to illustrate these themes.

\section{Overarching reflection: theoretically challenging but practically relevant}

Embedded in participant reflections was both a strong engagement with theory and clear development of practical career search and employability skills.

Engaging with theory. Students readily incorporated contemporary career theory, as discussed and used by the career practitioner, into discussions of their own career. They demonstrated an engagement with the central tenants of these theories and the ability to apply these to their own careers. For example, one student noted that

Inot only gained confidence in the process, but learning more about Greenhaus' theory allowed me to reflect on all my past decisions- such as high school leadership positions, university close to home, resigning from my part-time job of three years etc- and realise there is no right or wrong way of doing things. LV_3 


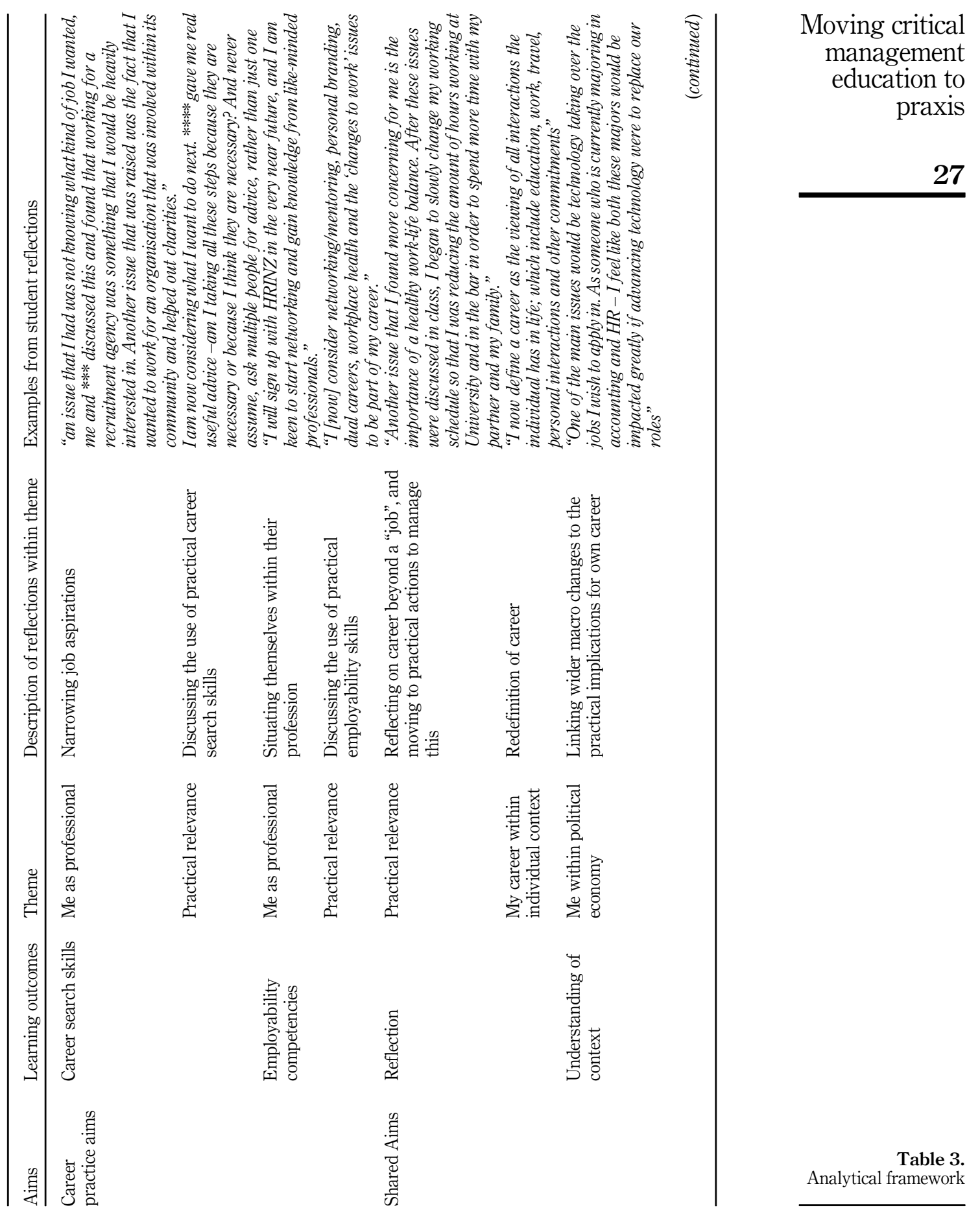




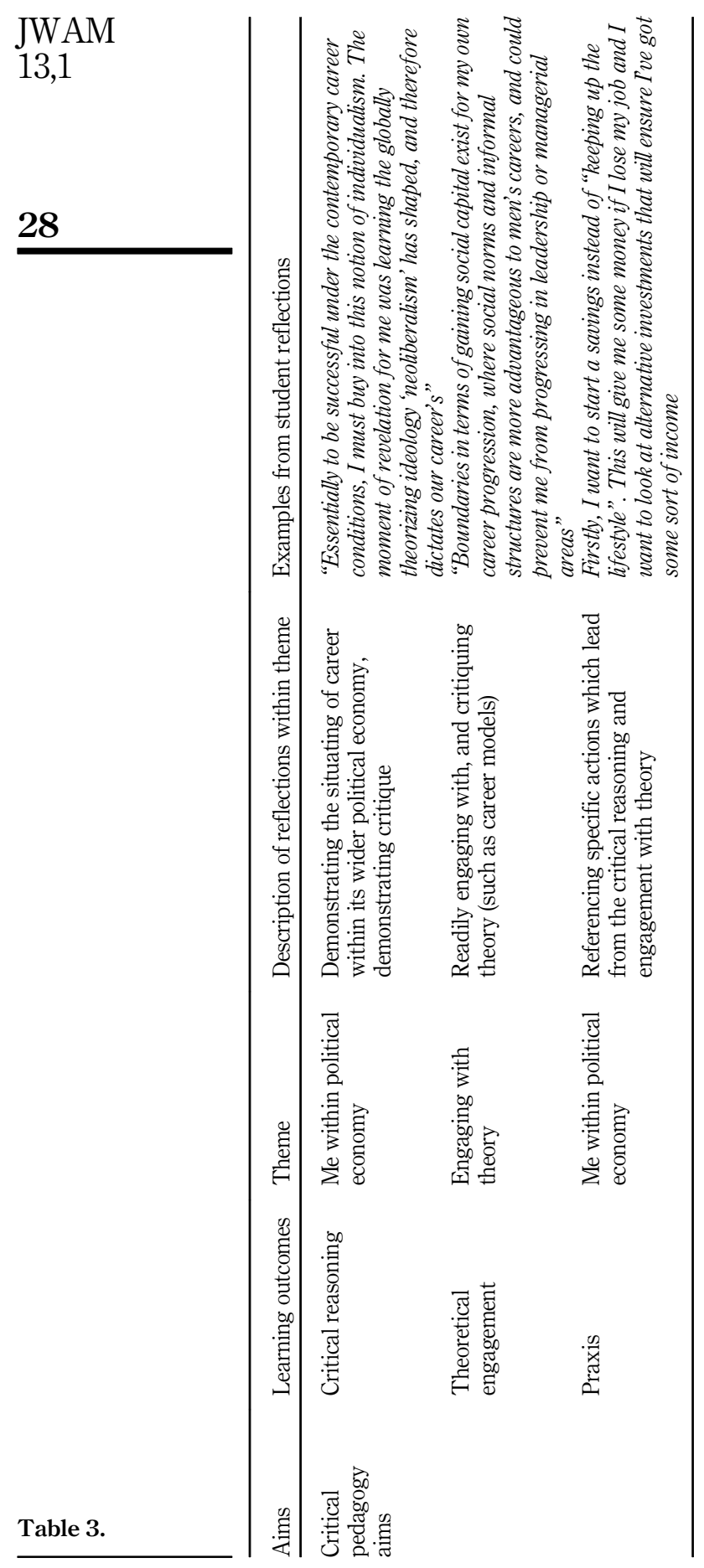


Another student applied a career model to help understand their multi-faceted aspirations within their wider career

My decision to continue with my studies and acquire more knowledge and skill. . . [and to] one day hopefully join Doctors Without Borders again or in fact any organisation with strong social awareness, in a position with more chances to grow can also be seen as an aspect of the Protean Career Development CM_3

For some students, the application of career theories to their original career definitions allowed them to start to critique the assumptions underpinning their original definitions

Originally, I defined a career as a series of jobs that reflect the values of the individual and help them to achieve their life goals. I now view this definition as an interpretation of contemporary models of career development, therefore I can recognise the flawsAO_3

Other students drew on wider meta-theories to make sense of links between wider systemic processes and their own career outcomes. For example, the student below draws on social capital theory in their application

Social-capital theory, which examines the relationships that we engage in and how we use those relationships within the employment market can also describe this issue where despite antidiscrimination legislation and EEO initiatives, horizontal and vertical segregation, and pay gaps based on gender and ethnicity (rather than human capital) persist. Boundaries in terms of gaining social capital exist for my own career progression, where social norms and informal structures are more advantageous to men's careers and could prevent me from progressing in leadership or managerial areas. AF_3

Practically relevant. Alongside the engagement at a theoretical level, students also reflected on how their experiences in the course were helping them to practically plan their own careers and how they might be involved in designing organisational career systems as HRM practitioners. For some, an understanding of the macro-context resulted in a reflection on practical strategies to navigate this context in their own career

I can now mitigate the issue of technology and changing trends as I will be more focused in an area. With a more active progression in entering the workforce at the position in my career which with earlier understanding and grasping what it's like in the real world; I can create strategies and habits on how to be as current as possible throughout the years. CC_3

For many, an increasing awareness of the importance of wider lifestyle and family considerations began to shape how they considered their next career moves

I have become far more aware of how lifestyle anchors what I value in a career. A good work/life balance is something I want in my career CD_3

For others, the opportunity to reflect and increase awareness of career options meant a refining of specific future career plans

An example of becoming in control and making specific tough decisions now was when ** and I discussed my future as a professional rugby player. I found my information gathering and knowledge of exactly where I wanted to go was not at a standard that reflected the position I wanted to achieve - which before was just to "play in Europe somewhere". This has now evolved to be ** wanting to "play for T" gooi Rugby Club in the Netherlands while giving myself 3 years to make the national Dutch side". The theory covered in class, paired with practical reflection that I now actively do by myself on a regular basis has improved my decision-making EK_3

The reflection also moved into the personal development realm, with students reflecting on their own strengths or areas for development and considering the influences on decisions they had made previously

Moving critical management education to praxis 
JWAM

13,1

I am now considering what I want to do next. Heather gave me real useful advice -am I taking all these steps because they are necessary or because I think they are necessary? And never assume, ask multiple people for advice, rather than just one MM_3

This application of the practical aspects of career saw some participants describe direct actions they had already undertaken as a result of their. For some, this was around building in work-life balance considerations

Another issue that I found more concerning for me is the importance of a healthy work-life balance. After these issues were discussed in class, I began to slowly change my working schedule so that I was reducing the amount of hours working at University and in the bar in order to spend more time with my partner and my family. I found that by doing this, I did become happier, slightly more active/ healthier, and my partner was happier that she was getting more attention from me. CW_3

Understanding practical steps also manifest in others proactively developing employability skills (Amoroso and Burke, 2018), such as in their active engagement in networking

I [now] consider networking/mentoring, personal branding, dual careers, workplace health and the "changes to work" issues to be part of my career. Networking because this makes any part of one's career more effective as building relationships can create opportunities that may have not otherwise arisen. Inow realise that I network in all parts of my life as I try to meet new people every week DS_3

Therefore, student reflections demonstrated learning about career development theory and practice. Alongside these spheres, students also demonstrated critical reasoning (Pollner, 1991), as presented next.

\section{Situating self and career within the micro, meso and macro context}

Student reflections demonstrated the development of critical reasoning as highlighted by their nuanced, multi-layered understanding that career has implications at the individual, organisational and macro-societal levels, as presented here.

Layer 1: My Career within the individual context (micro)

Students reflected on elements of their personal lives outside of work and how these might be included within their understanding of their own career. The reflection on wider elements of personal identities, activities and responsibilities led to a redefinition of the notion of career for many, as illustrated by the following

I now define a career as the viewing of all interactions the individual has in life; which include education, work, travel, personal interactions and other commitments. CC_3

For many students, this reflection centred on the role of personal relationships and in particular on the decision to raise children, within the context of their career.

I will adapt my career plan to ensure ... that I have both financial and psychological support before I start a family. Before becoming aware of these two issues in my previous career definition, I would have seen it suitable to have children at any point in my career, although, now I know that because of all the limitations and pressure on female managers, this is not possible, apparent natural life events need to be less natural and strategically planned AK_3

For some, they also reflected on the impact of caregiving of wider family members

I will take care of my parents when I turn 30, sending half of my salary as a tribute to sustain their life. This will have significant impact towards my future career plan CT_3

Throughout these reflections at an individual level, students began to explicitly situate the individual career within the wider context. 
an individual's progress not only in the workplace in an organization but within the society and community considering the contributing impacts of the physical environment, the people, education and health, culture and lifestyle, fun and recreation, personal growth that will contribute to the development of one's career. AS_3

Moving critical management education to praxis

Layer 2: My Career within the organisational context (meso)

Interwoven with reflections of individual level career considerations was a greater appreciation of their future working and organisational lives. For some, this meant a redefining of their desired career, creating a more focussed career search goal

an issue that I had was not knowing what kind of job I wanted, me and *** discussed this and found that working for a recruitment agency was something that I would be heavily interested in. Another issue that was raised was the fact that I wanted to work for an organisation that was involved within its community and helped out charities. JP_2

also helped me to see that there is the potential of human resource management and electronic business overlapping, which helped me with the uncertainty of choosing two separate career paths. KN_2

Students also began to see themselves as connected to a wider professional community, showing a movement away from seeing themselves as in a "pre-career" stage, waiting for their career to start once they graduated from university. This position reflects a job-based model of career and is reflected in many wider discussions of "work ready" graduates or "career ready" students (Amoroso and Burke, 2018).

I will sign up with HRINZ in the very near future, and I am keen to start networking and gain knowledge from like-minded professionals. While so far, I thought I would need to study more and gain more work experience, I have rethought this and will go for an opportunity if it arises. MM_2

\section{Layer 3: My Career within the political economy (Macro)}

Students also demonstrated the ability to both critique the macro environment and situate themselves within this critique. For example, students reflected on their previous career decisions and how these might be impacted by wider contextual changes

One of the main issues would be technology taking over the jobs I wish to apply in. As someone who is currently majoring in accounting and $\mathrm{HR}$ - I feel like both these majors would be impacted greatly if advancing technology were to replace our roles FT_3

In another example, a student considered the implications of gendered career differences on her own career

A second issue that challenged my definition of career is the fact that woman's careers differ from that of a male. In particular, the fact that women are underrepresented in managerial positions may have an impact on my future career. ... As a woman who has an interest in becoming an HR manager, I realise that the odds are against me and I will need to work hard to prevent stereotypes from affecting my career. LN_3

Within these reflections, the students demonstrated critical reasoning, engaging in depth with critical considerations of power relations

Essentially to be successful under the contemporary career conditions, I must buy into this notion of individualism. The moment of revelation for me was learning the globally theorizing ideology 
JWAM

13,1

"neoliberalism" has shaped, and therefore dictates our career's. ... Subsequently this forced me to become sceptical of what was deemed as "common sense" and the "societal norms" of careers. SP_3

These macro reflections did not remain at the abstract level, and there were several examples of how this led to action for students

Firstly, I want to start a savings instead of "keeping up the lifestyle". This will give me some money if I lose my job and I want to look at alternative investments that will ensure I've got some sort of income. RJ_3

In summary, student reflections demonstrate a movement towards an integrated understanding of theory and action. Moreover, rather than diluting an understanding of wider contextual factors, the inclusion of practice into the critical curriculum appears to enhance this understanding.

\section{Discussion and conclusion}

Our commitment to critical pedagogy remains intact, and we remain motivated to provide students with dialogic spaces to develop critical reasoning. However, what our experience has illustrated, is that while we seek to evoke transformation, and indeed as higher education teachers and researchers are charged to do so, our students come to the classroom with a range of motivations, perspectives and desired outcomes. We accept that many do not come to our classroom for an emancipatory experience but rather because they have the desire to gain an education in order to work in professional roles. And even those who do seek a deeper critique need to navigate a world of work that, in many ways, is not currently poised for transformation.

Fenwick (2005, p .6) describes how most examples of praxis are limited to critique, and previous work has not explored teaching practices to encourage this praxis. Fenwick thus calls for "developing course-based assignments that invite students to actively engage in praxis... [in order to] inform and often transform students" ethics so that social structures and systems will be improved.". It is this gap that we found ourselves exploring within the context of our teaching and attempted to address in the current research.

Initially, we were disheartened by this challenge and faced a pedagogical crisis; the critical management education approach we were committed to no longer served its purpose. We questioned whether bringing a functional practice into the critical management classroom was a form of "selling out". However, our exploration of critical and practice relevant aspirations revealed some overlap. What we were not anticipating was that the two, seemingly contradictory, approaches worked together to improve collective learning outcomes.

Thus, student reflections revealed that the course design facilitated achieving the practical objective of developing career competencies (Amoroso and Burke, 2018) and the critical objective of developing reflexivity (Cunliffe, 2003). Moreover, this course design provides an effective example of work-based learning (Paton et al., 2014). Through this reflexive experience, we have come to appreciate that bringing practice-relevant learning into the critical management classroom does not negate the importance of critique or the development of critical reasoning; rather, this approach makes critique within a business school context both more tenable and more tangible. We were no longer in the position of "fringe critic" within the context of disciplinary content-driven papers. Instead, the course was providing practical relevance, alongside deep critique, which according to Paton et al., is a key goal of "developing people as reflective, self-managing practitioners" (p. 563). Indeed, our experience resonates with Fenwick's (2005, p. 32) position that "[w]ithout productive engagement in action, analysis is hollow and circular; without reflective critical analysis, action is empty activism". 
Paton et al. (2014) describe the potential value of business schools as "offering counterintuitive viewpoints that challenge business mindsets" (p. 267), calling for learning that helps "managers understand the potentially disruptive power of ideas or theory" (Wall, 2016, p. 6). Our experience has provided an example of curriculum development that encourages the development of this critical reasoning, situating the theory and practice of careers within this broader context. Thus, our experience provides further insight into the process of integrating theory and practice (Hayes et al., 2019) and in particular offers an example of how course design can facilitate integrating practical and critical perspective within industry-based action-learning. Future research which, although beyond the scope of this paper, explores how different groups of students might experience curriculum changes would be beneficial.

While our experiences provide one example of how we might conceptualise blending practice-based experiences and critical pedagogy, achieving the aim of emancipatory action (praxis) still requires more work. In particular, examples of curriculum design that balance the real and pragmatic, needs of students to have work-relevant skills, alongside developing their ability to challenge assumptions and work towards more just organisations, are scarce and represent a significant potential for future work in this area.

\section{References}

Alvesson, M. and Willmott, H. (1992), Critical Management Studies, Sage, London.

Amoroso, L.M. and Burke, M. (2018), "Developing career-ready business students: three curriculum models", The Journal of Education for Business, Vol. 93 No. 8, pp. 420-429, doi: 10.1080/ 08832323.2018.1494533.

Bisman, J. (2011), "Engaged pedagogy: a study of the use of reflective journals in accounting education", Assessment and Evaluation in Higher Education, Vol. 36 No. 3, pp. 315-330.

Boje, D.M. and Al-Arkoubi, K. (2009), "Critical management education: beyond the siege", in Armstrong, S. and Fukami, C. (Eds), Handbook of Management Learning, Education and Development, Sage, London, pp. 104-125.

Braun, V. and Clarke, V. (2006), "Using thematic analysis in psychology", Qualitative Research in Psychology, Vol. 3 No. 2, p. 77.

Clegg, S. and Dunkerley, D. (1980), Organization, Class \& Control, Routledge and Kegan Paul, London.

Cunliffe, A.L. (2003), "Reflexive inquiry in organizational research: questions and possibilities", Human Relations, Vol. 56 No. 8, pp. 983-1003, doi: 10.1177/00187267030568004.

Cunliffe, A., Forray, J.M. and Knights, D. (2002), "Considering management education: insights from critical management studies", Journal of Management Education, Vol. 26 No. 5, p. 489.

Deetz, S. (1992), Democracy in an Age of Corporate Colonization: Developments in Communication and the Politics of Everyday Life, State University of Albany, NY, New York.

Dyer, S.L. and Hurd, F. (2015), “What's going on?' Developing reflexivity in the management classroom: from surface to deep learning and everything in between", The Academy of Management Learning and Education, Vol. 15 No. 2, pp. 287-303, doi: 10.5465/amle.2014.0104.

Dyer, S. and Hurd, F. (2016), "Changing perceptions about feminists and (still not) claiming a feminist identity", Gender and Education, online.

Dyer, S. and Hurd, F. (2018), "Equality as a threshold conception: challenging future manager's perceptions", Equality, Diversity and Inclusion: An International Journal, Vol. 37 No. 7, pp. 683-697.

Entwistle, N. (2000), "Promoting deep learning through teaching and assessment: a conceptual frameworks and educational contexts", Paper Presented at the TLRP Conference, Leicester, November.

Fenwick, T. (2005), "Ethical dilemmas of critical management education: within classrooms and beyond", Management Learning, Vol. 36 No. 1, pp. 31-48.
Moving critical management education to praxis 
JWAM

13,1

Freire, P. (1970), Pedagogy of the Oppressed, Seabury Press, New York.

Freire, P. (1992), Pedagogy of Hope: Reliving the Pedagogy of the Opressed, The Continuum Publishing Company, New York.

Grey, C. (2004), "Reinventing business schools: the contribution of critical management education", The Academy of Management Learning and Education, Vol. 3 No. 2, pp. 178-186.

Hayes, C., Bussey, S. and Graham, Y. (2019), "Illuminating undergraduate experiential and situated learning in podiatry clinical placement provision at a UK school of podiatric medicine", Higher Education, Skills and Work-based Learning, Vol. 9 No. 4, pp. 688-694, doi: 10.1108/HESWBL-102018-0119.

Humphries, M.T. and Dyer, S. (2005), "Introducing critical theory to the management classroom: an exercise building on jermier's 'life of mike”, Journal of Management Education, Vol. 29 No. 1, pp. 169-195, doi: 10.1177/1052562904264229.

Janse van Rensburg, J.T. and Goede, R. (2020), "Promoting career awareness among IT students in a South African context”, Higher Education, Skills and Work-Based Learning, Vol. 10 No. 3, p. 541.

Kek, M.Y.C.A. and Huijser, H. (2011), "The power of problem-based learning in developing critical thinking skills: preparing students for tomorrow's digital futures in today's classrooms", Higher Education Research and Development, Vol. 30 No. 3, pp. 329-341.

Lester, S. and Costley, C. (2010), "Work-based learning at higher education level: value, practice and critique", Studies in Higher Education, Vol. 35 No. 5, pp. 561-575, doi: 10.1080/03075070903216635.

Mannay, D. (2010), "Making the familiar strange: can visual research methods render the familiar setting more perceptible?”, Qualitative Research, Vol. 10, pp. 91-111.

Miller, R.J. and Maellaro, R. (2016), "Getting to the root of the problem in experiential learning: using problem solving and collective reflection to improve learning outcomes", Journal of Management Education, Vol. 40 No. 2, pp. 170-193.

Paton, S., Burt, G. and Chia, R. (2014), "Relevance or 'relevate'? How university business schools can add value through reflexively learning from strategic partnerships with business", Management Learning, Vol. 45 No. 3, pp. 267-288, doi: 10.1177/1350507613479541.

Perriton, L. (2007), "Really useful knowledge? Critical Management Education in the UK and the US", Scandinavian Journal of Management, Vol. 23 No. 1, pp. 66-83.

Pollner, M. (1991), "Left of ethnomethodology: the rise and decline of radical reflexivity", American Sociological Review, Vol. 56 No. 3, pp. 370-380.

Ramsey, C. (2011), "Provocative theory and a scholarship of practice", Management Learning, Vol. 42 No. 5, pp. 469-483, doi: 10.1177/1350507610394410.

Spicer, A., Alvesson, M. and Kärreman, D. (2009), "Critical performativity: the unfinished business of critical management studies", Human Relations, Vol. 62 No. 4, p. 537.

Super, D.E. (1980), “A life-span, life-space, approach to career development”, Journal of Vocational Behavior, Vol. 13, pp. 282-298.

Walker, K., Dyck, B., Zhang, Z. and Starke, F. (2019), "The use of praxis in the classroom to facilitate student transformation”, Journal of Business Ethics, Vol. 2019 No. 157, pp. 199-216.

Wall, T. (2016), "Žižekian ideas in critical reflection: the tricks and traps of mobilising radical management insight”, Journal of Work-Applied Management, Vol. 8 No. 1, pp. 5-16, doi: 10.1108/ JWAM-04-2016-0005.

\section{Further reading}

Currie, G. and Knights, D. (2003), "Reflecting on a critical pedagogy in MBA education", Management Learning, Vol. 34 No. 1, pp. 27-50.

Elliot, C. (2003), "Representations of the intellectual: insights from Gramsci on management education", Management Learning, Vol. 34 No. 4, pp. 411-427. 
Reynolds, M. (1999), "Grasping the nettle: possibilities and pitfalls of a critical management pedagogy", British Journal of Management, Vol. 10 No. 2, pp. 170-184.

Vince, R. (2010), "Anxiety, politics and critical management education”, British Journal of Management, Vol. 21 No. s1, pp. s26-s39.

Moving critical management education to praxis

Corresponding author

Fiona Hurd can be contacted at: fiona.hurd@aut.ac.nz

For instructions on how to order reprints of this article, please visit our website: www.emeraldgrouppublishing.com/licensing/reprints.htm Or contact us for further details: permissions@emeraldinsight.com 